\title{
COMMENTARY
}

\section{Open the lung with high-frequency oscillation ventilation or conventional mechanical ventilation? It may not matter!}

\author{
Vito Fanelli ${ }^{1,2}$ and Sangeeta Mehta ${ }^{* 2,3}$ \\ See related research by Krebs et al., http://ccforum.com/content/14/5/R183
}

\begin{abstract}
The 'open lung' approach has been proposed as a reasonable ventilation strategy to mitigate ventilatorinduced lung injury (VILI) and possibly reduce acute respiratory distress syndrome (ARDS)-related mortality. However, several randomized clinical trials have failed to show any significant clinical benefit of a ventilation strategy applying higher positive end-expiratory pressure (PEEP) and low tidal volume. Dispute regarding the optimal levels of PEEP in ARDS patients represents the substrate for a translational research effort from the bedside to the bench, driving animal studies aimed at elucidating which ventilation strategies reduce biotrauma, considered one of the most important driving forces of VILI and ARDS-related multi-organ failure and mortality. Inappropriate values for end-inspiratory or end-expiratory pressure have clear potential to damage a lung predisposed to VILI. In the heterogeneous environment of the ARDS 'baby lung,' lung recruitment and the avoidance of tidal overstretch with high-frequency oscillation ventilation or conventional mechanical ventilation, guided by respiratory mechanics, appears to reduce VILI.
\end{abstract}

In the previous issue of Critical Care, Krebs and colleagues [1] elegantly demonstrated that an 'open lung' ventilation strategy using high-frequency oscillation ventilation (HFOV) or conventional mechanical ventilation (CMV) has the potential to mitigate ventilator-induced lung injury (VILI) compared to low positive

\footnotetext{
*Correspondence: geeta.mehta@utoronto.ca

${ }^{3}$ Research Director, Medical/Surgical Intensive Care Unit, Department of Medicine, Mount Sinai Hospital, 600 University Ave \#18-216, Toronto, Canada M5G 1X5
} Full list of author information is available at the end of the article end-expiratory pressure (PEEP) CMV. Using two animal models of lung injury (saline-lavage and lipopolysaccharide (LPS)), they randomized rats to three ventilation strategies: CMV and low PEEP, CMV and high PEEP (pursuing an 'open lung' strategy), and HFOV. In both CMV groups protective ventilation was ensured by limiting tidal volume to $6 \mathrm{ml} / \mathrm{kg}$. Compared to the low PEEP group, the open lung approach, whether applied with CMV or HFOV, was able to reduce VILI, as demonstrated by improvements in the respiratory system elastance, oxygenation, and histological lung injury score, as well as reduced expression of inflammatory cytokines. Moreover, comparing rats randomized to the two open lung approaches, HFOV resulted in better oxygenation than CMV with high PEEP, but elastance, lung injury and cytokine levels did not differ between the two groups.

Pivotal animal studies have eloquently demonstrated the deleterious effects of mechanical ventilation in initiating or perpetuating lung injury [2], and these studies have provided invaluable input for human studies, culminating in the ARDSnet trial showing that lungprotective tidal volume limitation reduces acute respiratory distress syndrome (ARDS)-associated mortality [3]. In addition to tidal alveolar overstretching, tidal alveolar recruitment/derecruitment has also been implicated in VILI [2]. An 'open lung' approach [4], applying higher PEEP levels together with lung recruitment maneuvers, has been proposed to avoid cyclic alveolar recruitment/ derecruitment during mechanical ventilation, to reduce biotrauma, and reduce the spread of inflammatory mediators from the lung into the systemic circulation [2]. Despite the promise of animal studies, recent multicenter clinical trials have failed to demonstrate the superiority of higher PEEP versus lower PEEP levels in patients with ARDS [5]. An 'open lung' approach with higher levels of PEEP compared to a lower PEEP protective-ventilation strategy should increase the end-expiratory lung volume through alveolar recruitment, and also avoid overinflation of non-dependent aerated alveoli [6]. One 
possible explanation for the lack of demonstrated benefit of higher PEEP in human trials is that the percentage of recruitable lung is quite variable in ARDS patients [6], such that not all ARDS patients benefit from higher levels of PEEP, and a tailored ventilatory strategy is advised when applying higher PEEP levels [5].

HFOV is theoretically ideal for lung protection, as it delivers a relatively high mean airway pressure, and extremely small tidal volumes at very high respiratory frequencies ( 3 to $15 \mathrm{~Hz}$ ), with the objectives of avoiding recruitment/derecruitment and tidal overstretch [7]. In animal models, HFOV has been shown to improve gas exchange, and reduce inflammation and pathologic changes, in comparison with high volume/high pressure conventional ventilation strategies [8]. While some animal studies also demonstrate these benefits when HFOV is compared with conventional lung-protective ventilation strategies, the results are not as consistent [8]. In adults with ARDS, several observational trials have shown improvements in gas exchange with HFOV [7,9], while two randomized controlled trials failed to demonstrate any clear advantages to HFO compared with CMV [10,11]. However, inferences from these randomized trials are limited by potential biases, small sample size, and use of now-dated, potentially injurious CMV strategies.

A notable strength of the study performed by Krebs and colleagues was the physiological method used to set PEEP in the CMV open lung group, thus tailoring the ventilator strategy based on respiratory mechanics. The PEEP level was set to achieve the minimal static elastance of the respiratory system, compared with strategies that set PEEP based on oxygenation criteria [12-14], or a $\mathrm{PEEP} / \mathrm{FiO}_{2}$ combination table [15]. Using an elastancetargeted approach to set PEEP potentially allows identification of the PEEP level that achieves both recruitment of atelectatic lung, and avoidance of overinflation, thus minimizing the deleterious effects of PEEP. Moreover, the investigators set the HFOV mean airway $2 \mathrm{cmH}_{2} \mathrm{O}$ above the mean airway pressure measured during CMV and 'best PEEP' corresponding to the minimum respiratory system elastance: in this way the CMV and HFOV open lung approaches were very comparable.

There are notable limitations to this study. First, the major differences between the 'open lung' and low PEEP groups were observed primarily in the saline lavage model, and not in the LPS model. As the authors state, the LPS model was selected because it mimics the acute lung injury associated with sepsis. At baseline, however, the LPS group did not show any differences in $\mathrm{PaO}_{2} / \mathrm{FiO}_{2}$ ratio or respiratory mechanics compared to uninjured lungs; thus, not surprisingly, the LPS animals did not clearly manifest the beneficial nor the detrimental effects of higher PEEP. In contrast to the LPS model, the saline lavage model exhibits greater lung recruitability in response to higher levels of PEEP and mean airway pressure [16]. It would be interesting in future studies to compare the two ventilatory strategies in a model with greater impairment of respiratory mechanics and higher opening pressures (such as intra-tracheal hydrochloric acid instillation and intravenous oleic acid administration), in which higher levels of PEEP and mean airway pressures could induce over-inflation [16]. Second, the authors failed to use a physiological approach to set PEEP in the low PEEP group [17]; and they used an arbitrary low PEEP level that allowed them to keep the rats alive. The derecruitment and atelectasis associated with this strategy could in fact contribute to VILI in this group, and affect the study's overall conclusions.

In conclusion, a physiological-based approach to recruit the lungs may be useful to mitigate VILI. Furthermore, when mechanical ventilator settings are tailored using respiratory mechanics, HFOV and conventional mechanical ventilation seem to be equivalent to achieve the goal. How these findings will translate to clinical studies of adults with ARDS remains to be determined.

\section{Abbreviations}

ARDS, acute respiratory distress syndrome; CMV, conventional mechanical ventilation; HFOV, high-frequency oscillation ventilation; LPS, lipopolysaccharide; PEEP, positive end-expiratory pressure; VILI, ventilatorinduced lung injury.

\section{Competing interests}

The authors declare that they have no competing interests.

\section{Author details}

'The Keenan Research Centre of the Li Ka Shing Knowledge Institute of St Michael's Hospital, 30 Bond Street, Toronto, Ontario, Canada M5B 1W8. Interdepartmental Division of Critical Care, University of Toronto, Ontario, Canada. ${ }^{3}$ Research Director, Medical/Surgical Intensive Care Unit, Department of Medicine, Mount Sinai Hospital, 600 University Ave \#18-216, Toronto, Canada M5G 1 X5.

\section{Published: 9 December 2010}

\section{References}

1. Krebs J, Pelosi P, Tsagogiorgas C, Zoeller L, Rocco PRM, Yard B, Luecke T: Open lung approach associated with high-frequency oscillatory or low tidal volume mechanical ventilation improves respiratory function and minimizes lung injury in healthy and injured rats. Crit Care 2010, 14:R183.

2. Tremblay LN, Slutsky AS: Ventilator-induced lung injury: from the bench to the bedside. Intensive Care Med 2006, 32:24-33.

3. The Acute Respiratory Distress Syndrome Network:Ventilation with lower tidal volumes as compared with traditional tidal volumes for acute lung injury and the acute respiratory distress syndrome. The Acute Respiratory Distress Syndrome Network. N Engl J Med 2000, 342:1301-1308.

4. Lachmann B: Open up the lung and keep the lung open. Intensive Care Med 1992, 18:319-321.

5. Briel M, Meade M, Mercat A, Brower RG, Talmor D, Walter SD, Slutsky AS, Pullenayegum E, Zhou Q, Cook D, Brochard L, Richard JC, Lamontagne F, Bhatnagar N, Stewart TE, Guyatt G: Higher vs lower positive end-expiratory pressure in patients with acute lung injury and acute respiratory distress syndrome: systematic review and meta-analysis. JAMA 303:865-873.

6. Grasso S, Fanelli V, Cafarelli A, Anaclerio R, Amabile M, Ancona G, Fiore T: Effects of high versus low positive end-expiratory pressures in acute respiratory distress syndrome. Am J Respir Crit Care Med 2005, 171:1002-1008. 
7. Chan KP, Stewart TE, Mehta S: High-frequency oscillatory ventilation for adult patients with ARDS. Chest 2007, 131:1907-1916.

8. Ferguson N, Slutsky A: High-frequency ventilation: lessons learned and future directions. In Civetta, Taylor and Kirby's Critical Care. 4th edition. Edited by Wilkins LW. Philadelphia: Lippincott Williams \& Wilkins; 2009:2029-2041.

9. Mehta S, Granton J, MacDonald RJ, Bowman D, Matte-Martyn A, Bachman T, Smith T, Stewart TE: High-frequency oscillatory ventilation in adults: the Toronto experience. Chest 2004, 126:518-527.

10. Derdak S, Mehta S, Stewart TE, Smith T, Rogers M, Buchman TG, Carlin B, Lowson S, Granton J: High-frequency oscillatory ventilation for acute respiratory distress syndrome in adults: a randomized, controlled trial. Am J Respir Crit Care Med 2002, 166:801-808.

11. Bollen CW, van Well GT, Sherry T, Beale RJ, Shah S, Findlay G, Monchi M, Chiche JD, Weiler N, Uiterwaal CS, van Vught AJ: High frequency oscillatory ventilation compared with conventional mechanical ventilation in adult respiratory distress syndrome: a randomized controlled trial [ISRCTN24242669]. Crit Care 2005, 9:R430-439.

12. Muellenbach RM, Kredel M, Said HM, Klosterhalfen B, Zollhoefer B, Wunder C, Redel A, Schmidt M, Roewer N, Brederlau J: High-frequency oscillatory ventilation reduces lung inflammation: a large-animal 24-h model of respiratory distress. Intensive Care Med 2007, 33:1423-1433.

13. von der Hardt K, Kandler MA, Fink L, Schoof E, Dotsch J, Brandenstein O, Bohle RM, Rascher W: High frequency oscillatory ventilation suppresses inflammatory response in lung tissue and microdissected alveolar macrophages in surfactant depleted piglets. Pediatr Res 2004, 55:339-346.

14. Vazquez de Anda GF, Hartog A, Verbrugge SJ, Gommers D, Lachmann B: The open lung concept: pressure-controlled ventilation is as effective as high-frequency oscillatory ventilation in improving gas exchange and lung mechanics in surfactant-deficient animals. Intensive Care Med 1999, 25:990-996.

15. Imai Y, Slutsky AS: High-frequency oscillatory ventilation and ventilatorinduced lung injury. Crit Care Med 2005, 33(3 Suppl):S129-134.

16. Grasso S, Stripoli T, Sacchi M, Trerotoli P, Staffieri F, Franchini D, De Monte V, Valentini V, Pugliese P, Crovace A, Driessen B, Fiore T: Inhomogeneity of lung parenchyma during the open lung strategy: a computed tomography scan study. Am J Respir Crit Care Med 2009, 180:415-423.

17. Rotta AT, Gunnarsson B, Fuhrman BP, Hernan LJ, Steinhorn DM: Comparison of lung protective ventilation strategies in a rabbit model of acute lung injury. Crit Care Med 2001, 29:2176-2184.

doi:10.1186/cc9343

Cite this article as: Fanelli V, Mehta S: Open the lung with high-frequency oscillation ventilation or conventional mechanical ventilation? It may not matter! Critical Care 2010, 14:1010. 